\title{
Computer modeling of the process of depth of soil treatment
}

\author{
Alshyn Altybayev ${ }^{1}$, Adilbek Zhanbyrbayev ${ }^{1}$, Besarion Meskhi ${ }^{2}$, Dmitriy Rudoy $^{2}$, Anastasiya \\ Olshevskaya $^{2, *}$, and Anna Prohorova ${ }^{2}$ \\ ${ }^{1}$ Scientific Production Center of Agricultural Engineering LTD, Almaty, Kazakhstan \\ ${ }^{2}$ Don State Technical University, Gagarin square, 1, Rostov-on-Don, 344000, Russia
}

\begin{abstract}
The article is devoted to the problem of creating methodological foundations for research on the processes of machine use in agriculture. The basic approaches and principles of the formation of domain models are outlined, as the output processes of the functioning of the technological system of tillage and depth of cultivation are taken. A mathematical model of the process of depth of soil cultivation is proposed, which allows the implementation of research using modern software and hardware systems through a computer experiment.
\end{abstract}

\section{Introduction}

The problem of the efficiency of technology is an integral part of industrializing of production, and the processes of implementing mechanized field work in agriculture is no exception. The effectiveness of the mechanization system of field work is largely determined by the level of use of machine-tractor units (MTU). The fundamental difference between MTUs and machine units of other types is that the technological process is carried out by moving the entire unit across the field or directly through the material being processed. In addition, the characteristics of the latter are formed under the influence of natural and climatic conditions, and the technological processes themselves are implemented over considerable periods of time and large areas. One of the fundamental tradeoffs in this case is that the quality of the technological operation decreases with increasing complexity of the mechanical design. An analysis of scientific research showed that more than $50 \%$ of the mechanized work deviates from agrotechnical requirements, while $40-50 \%$ of the resource potential is spent on the technological process of cultivating the soil for grain crops. $[1,2,3$, 4].

Agrotechnical requirements for performing a technological operation by means of mechanized field work are formulated in the form of quality indicators $[5,6,7]$. The main indicator is the depth of soil cultivation, estimated by the accuracy criterion, the mathematical expression of which is the average value $(\overline{\mathrm{h}})$ in the tolerance range $\left(h_{t r}\right)$, i.e.

$$
\bar{h} \leq\left|h_{t r}\right|
$$

The researchers found that the physical characteristics of soil (surface roughness and

\footnotetext{
*Corresponding author: oav.donstu@gmail.com
} 
soil hardness) significantly influenced the quantity and quality of functioning of the MTUsoil technological system. At the same time, the laws of this influence are usually investigated in published studies using experimental data, which has very limited application. In addition, the traditional methodology for the study of technological processes proceeds from a simplified representation of the influence of the soil factor $[8,9]$, which may even disregard this factor. Alternatively, this factor may be described only in the most general abstract terms. All this is largely due to the lack of a methodological approach to modeling the processes of machine use, including the study of the agro-technological properties of machine-tractor units during their operation.

The purpose of the present study is to develop a methodological basis for modeling the input parameters of the quality of the technological operation in order to calculate the theoretical behavior of the technological system from the perspective of increasing the efficiency of mechanized processes in the field work.

\section{Materials and Methods}

The systemic analysis of this area of research is based on the following idea:

- the current problem of the efficiency of mechanized production is associated with the management of material and technical and technological resources of real production processes. Technological resources include, first of all, the optimal (rational) regulation of the functional elements of the technical system. This requires knowledge of the patterns of change in the agro-technological properties of MTUs. This in turn ensures the optimal adjustment of technological elements of the technical system for implementing quality requirements in the technological operation as a whole;

- at the current level of development of mechanizing field work, the agro-technological property (quality) of the functioning of the technological system is largely due to the kinematics of the morphological structure of the machine-tractor unit as a whole;

- in the context of the digitalization of the economy, the use of modern software and hardware systems in applied research is a fundamental condition for their effectiveness.

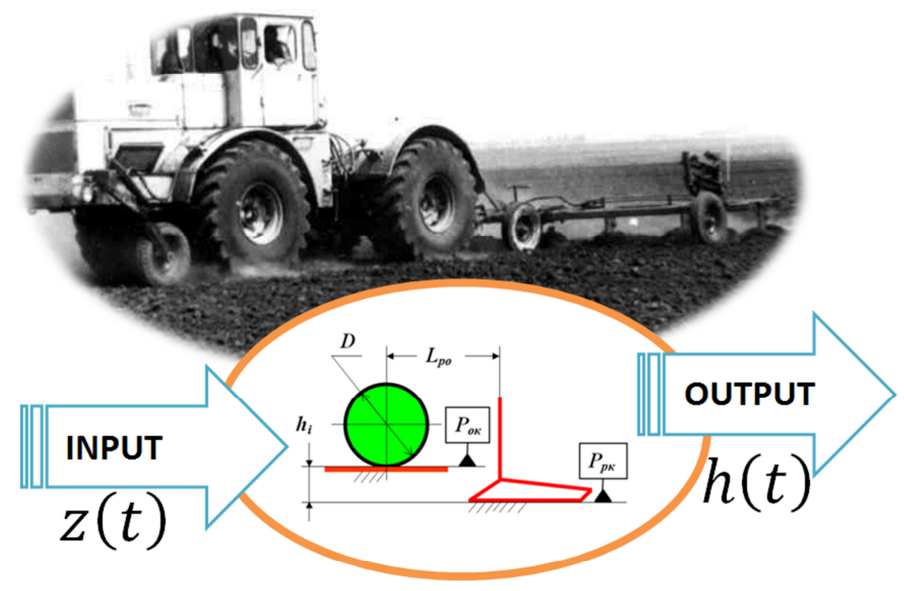


Fig. 1. Formulation of a conceptual model of the process of soil cultivation depth

\section{Results and Discussion}

Structural and morphological analysis of the technological system for mechanical treatment of the soil [10] shows that the conceptual model of the process of depth of soil treatment from the standpoint of studying the agro-technological properties of MTU in terms of the depth of soil treatment can be reduced to the study of spatial orientation. All of that means the changes in the spatial orientation of the relative positions of the planes of the support wheel of the gun and the cutting edges of the work tool of the MTU in the longitudinally vertical plane (Fig. 1).

At the same time, the essence of the model is described by the following categories: plane $\left(\mathrm{P}_{\mathrm{ok}}\right)$ of the support wheel (D); the plane of the cutting edges of the work tool $\left(\mathrm{P}_{\mathrm{pk}}\right)$;soil plane (characterized by roughness of the field surface); coordinates of the interposition between them. Input variables (factors) are: uneven soil surface, which is a disturbing factor, technical and technological parameters of the tool. The output variables are a set of measurement results of the observed parameter of the quality indicator of the technological operation, for example, the depth of the soil treatment.

Mathematical model establishes quantitative relationships between system elements that are essential for the formation of the process of soil cultivation depth. Based on the accepted conceptual model, a mathematical model of the process of forming the depth of the work tool (as an analogue of the depth of soil treatment) can be obtained based on the geometric structure of the mutual position of the main elements of the process of depth of soil treatment (Fig. 2).

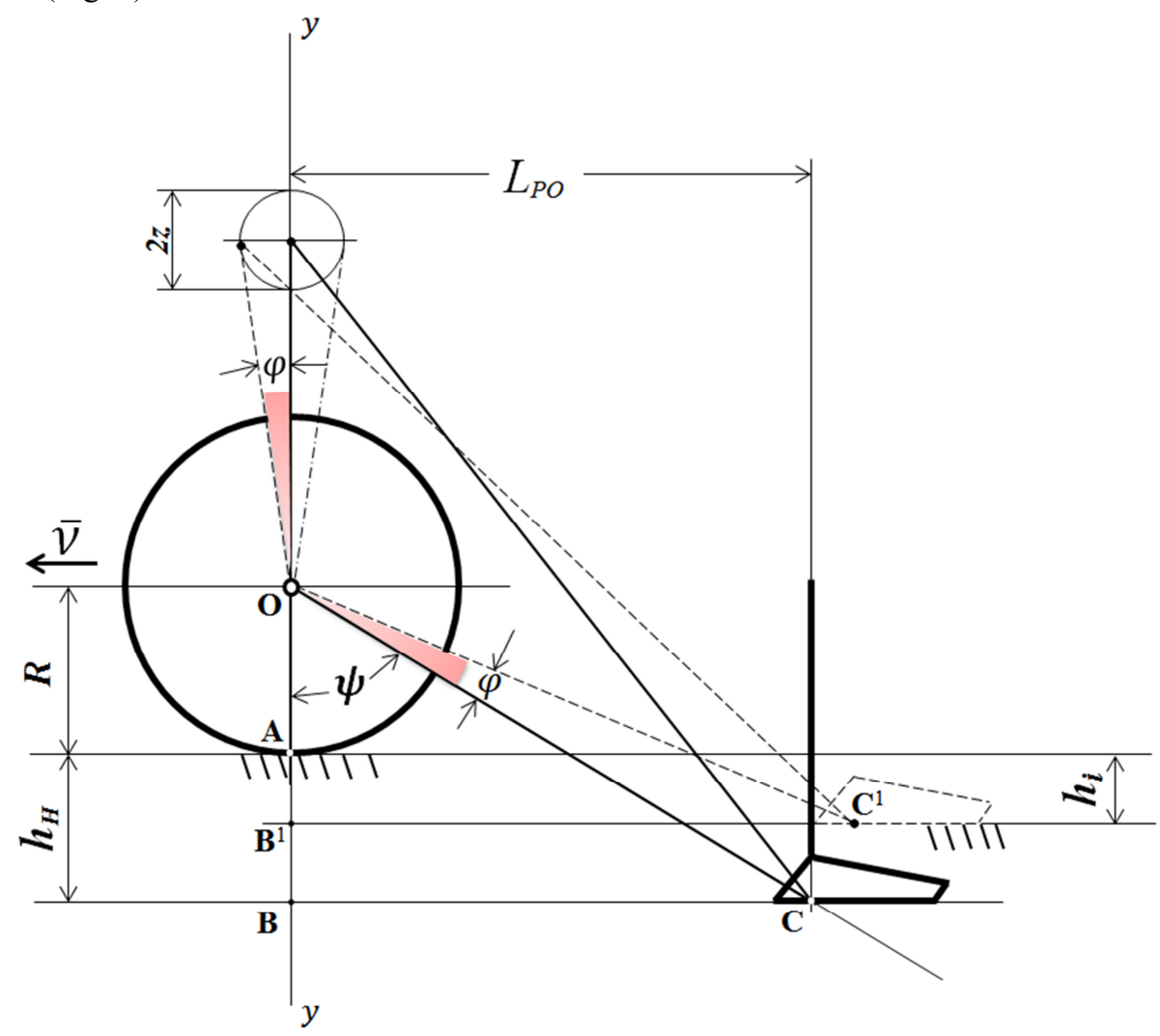


Fig. 2. Formulation of a mathematical model of the process of soil cultivation depth

Based on the diagram it can be said that during the work of MTU the changes in the depth of the work tool with the initial value $h_{H}$ with other similar conditions happen because of the angular fluctuations of the technical system regarding to the contact point of the support wheel with the soil surface. The following assumptions can be made for the theoretical modeling:

- the movement of the support wheel on the soil surface happens without sliding;

- the disturbing effect of uneven soil surface is transmitted through the contact of undeformed solid bodies

The current position of the running depth $\left(h_{i}\right)$ of the work tool is defined as the projection onto the y-y axis passing through the point of contact of the plane of the support wheel with the soil surface in a vertically longitudinal plane. From the ratio of the triangles of $\mathrm{OBC}$ and $\mathrm{OB}$ 'C', we obtain the following expression describing the state of the technological system of soil treatment at each moment in time.

$$
h_{i}=\mathrm{AB}^{1}=\sqrt{\left(\frac{D}{2}+h_{H}\right)^{2}+L_{P O}^{2} \cdot \cos \left(\psi_{H} \pm \varphi_{i}\right)}-\frac{D}{2}
$$

After a simple conversion, we get

$$
h_{i}=\left(R+h_{H}\right) \cos \varphi_{i}-L_{P O} \cdot \sin \varphi_{i}-R
$$

Where:

$h_{i} \quad$ the current value of the depth of the work tool;

$h_{H} \quad$ the value of the initial technological adjustment of the unit;

$\varphi_{i} \quad$ the value of the angular deviation from the initial state;

$L_{P O} \quad$ the distance of the work tool to the support wheel, a parameter of the technical system;

$R \quad$ support wheel radius, technical system parameter $(R=D / 2)$

Thus, expression (3) is a simulation model of the process of forming the depth of soil treatment during the operation of the technological soil treatment system - "MTU-soil". The task of a computer experiment is to form a data array $\left\{h_{i}\right\}$, and after its mathematicalstatistical processing to evaluate the fulfillment of condition (1) depending on changes in the design and technological parameters of the MTU and the state of the MTU working conditions. The flow of input variables $\{z\}$, expressed through angular fluctuations of the technical system relative to the initial position, is easily implemented by drawing random numbers with specified statistical parameters, regardless of the language and technology of the programming tools. Consequently, controlled input variables, which the reliability of the experiment, can be obtained. The results of computer experiments implemented in various programming formats (Excel, Matlab) showed identical results. Fig. 3 shows a fragment of the preliminary results of a computer experiment in order to establish the laws of change [11]. 


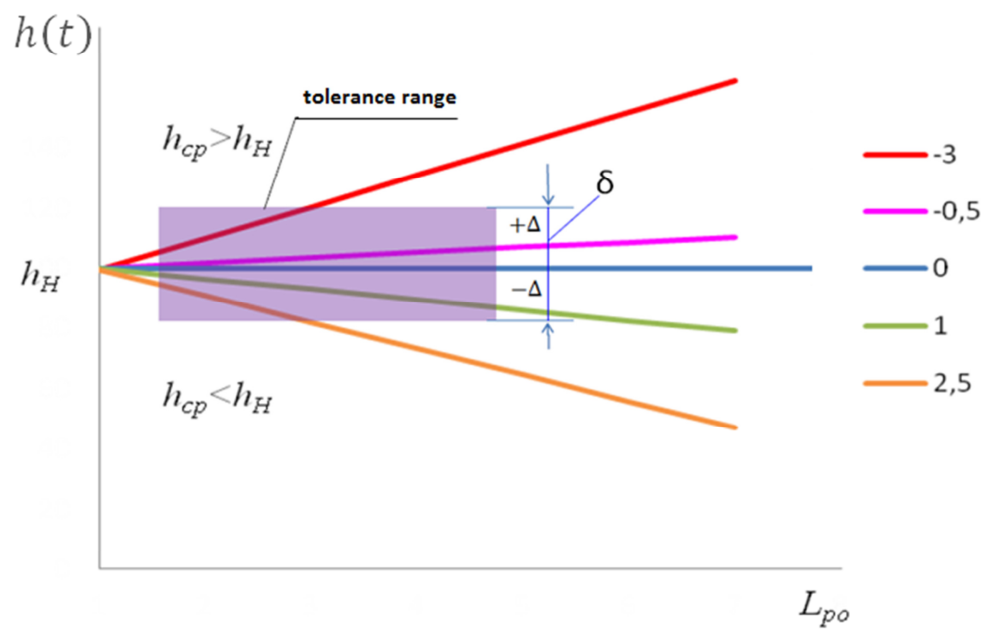

Figure 3. The results of a computer study

Based on the results of the experiment, finding the average value of the processing depth $(\bar{h})$ in the tolerance field is a function of the distance of the work tool from the support wheel $\left(L_{P O}\right)$, as well as the unevenness of the surface of the treated field, specified by a statistical parameter. The obtained patterns can be taken as the basis for the synthesis of the quality management system for the implementation of the technological operation of soil treatment at the design stage of mechanization tools and during their operation. Consequently, it contributes to optimization of structural and technological schemes to ensure the uniform depth of soil treatment. The operational measures, which were developed based on the differentiated settings of the work tools in different rows, increase the accuracy of the work tools during the functioning of the technological soil processing system, which ultimately leads to an increase in MTU productivity during the shift.

\section{Conclusions}

1. The kinematic entity of the concept of the depth of soil treatment is formulated, which characterizes the quality of the technological operation in the production of mechanized fieldwork.

2. A mathematical model of the process of depth of soil treatment is proposed, which allows the implementation of research using modern hardware-software complexes through a computer experiment.

3. Based on the results of a computer experiment, it was found that the dynamics of the depth of soil treatment in other similar conditions is a function of the distance of the work tool from the support wheel, as well as the surface roughness of the treated field.

4. Modeling the relative positions of functional structural elements and their relations in the coordinate system within the framework of this technological system is easily formalized and simply implemented by modern software tools.

The work was carried out within the framework of financing of the Ministry of Agriculture of the Republic of Kazakhstan NTP "Scientific support of the agro-industrial complex" 


\section{References}

1. S. Kambulov, I. Bozhko, A. Olshevskaya, MATEC Web of Conferences, 224, 05022 (2018) https://doi.org/10.1051/matecconf/201822405022

2. G. Burton, D. Shend, C. Cambell, Géotechnique Letters, 4, 2, 88-93 (2015) http://doi.org/10.1680/geolett.14.00003

3. J. Konrad, M. Lebeau, Canadian Geotechnical Journal, 52, 12, 2067-2076 (2015) https://doi.org/10.1139/cgj-2014-0300

4. V. Medvedev, A. Slovinska-Yurkevich, M. Brik, Gruntoznavstvo, 13, 1-2, 5-22 (2012)

5. Y. Gao, D. Sun, Z. Zhu, Y. Xu, Acta Geotechnica, 1-12 (2018)

6. S. Parkhomenko, G. Parkhomenko, Innovatsii v sel'skom khozyaystve, 3, 18, 40-47 (2016)

7. G. Parkhomenko, S. Parkhomenko, Trudy GOSNITI, 122, 87-91 (2016)

8. G. Parkhomenko, S. Parkhomenko, Khraneniye i pererabotka zerna, 1, 209, 55-60 (2017)

9. Yu.A. Ivanov, V.I. Pakhomov, S.I. Kambulov, D.V. Rudoi, MATEC Web of Conferences, 224, 05023 (2018) ) https://doi.org/10.1051/matecconf/201822405023

10. E.P. Klyuchka, V.V. Radin, L.M. Groshev, S.I. Kambulov, MATEC Web of Conferences, 226, 02020 (2018) https://doi.org/10.1051/matecconf/201822602020

11. S.I. Kambulov, V.B. Rykov, E.I. Trubilin, Research Journal of Pharmaceutical, Biological and Chemical Sciences, 4, 599-606 (2018) 